\title{
Recent Developments of Reconfigurable Antennas for Current and Future Wireless Communication Systems
}

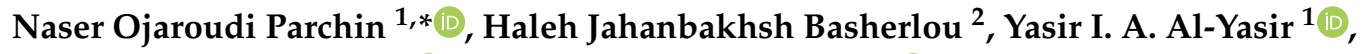 \\ Raed A. Abd-Alhameed ${ }^{1}{ }^{(1)}$, Ahmed M. Abdulkhaleq ${ }^{1,3}{ }^{-1}$ and James M. Noras ${ }^{1}$ \\ 1 Faculty of Engineering and Informatics, School of Electrical Engineering and Computer Science, \\ University of Bradford, Bradford BD7 1DP, UK; Y.I.A.Al-Yasir@bradford.ac.uk (Y.I.A.A.-Y.); \\ R.A.A.Abd@bradford.ac.uk (R.A.A.-A.); A.Abd@sarastech.co.uk (A.M.A.); jmnoras@bradford.ac.uk (J.M.N.) \\ 2 Microwave Technology Company, P 14, Sa'adi Avenue, Vezarat Kar Street, Azadi Street, Tehran, Iran; \\ Hale.Jahanbakhsh@gmail.com \\ 3 SARAS Technology Limited, Leeds LS12 4NQ, UK \\ * Correspondence: N.OjaroudiParchin@Bradford.ac.uk; Tel.: +44-734-143-6156
}

Received: 24 December 2018; Accepted: 18 January 2019; Published: 26 January 2019

\begin{abstract}
Reconfigurable antennas play important roles in smart and adaptive systems and are the subject of many research studies. They offer several advantages such as multifunctional capabilities, minimized volume requirements, low front-end processing efforts with no need for a filtering element, good isolation, and sufficient out-of-band rejection; these make them well suited for use in wireless applications such as fourth generation $(4 \mathrm{G})$ and fifth generation $(5 \mathrm{G})$ mobile terminals. With the use of active materials such as microelectromechanical systems (MEMS), varactor or p-i-n (PIN) diodes, an antenna's characteristics can be changed through altering the current flow on the antenna structure. If an antenna is to be reconfigurable into many different states, it needs to have an adequate number of active elements. However, a large number of high-quality active elements increases cost, and necessitates complex biasing networks and control circuitry. We review some recently proposed reconfigurable antenna designs suitable for use in wireless communications such as cognitive-ratio (CR), multiple-input multiple-output (MIMO), ultra-wideband (UWB), and 4G/5G mobile terminals. Several examples of antennas with different reconfigurability functions are analyzed and their performances are compared. Characteristics and fundamental properties of reconfigurable antennas with single and multiple reconfigurability modes are investigated.
\end{abstract}

Keywords: 4G; 5G; CR; MIMO; reconfigurable antenna; switch; UWB; WiMAX; WLAN; wireless communications

\section{Introduction}

Due to their attractive advantages such as multi-band function, steerable radiation patterns and polarization diversity, which can reduce the size, complexity, and cost of an antenna while improving the total performance of a radio frequency (RF) system, reconfigurable antennas have been studied intensively in recent years [1,2]. Such antennas can facilitate multiple services in a compact structure and are good candidates for use in the future generation of mobile and wireless communication systems [3]. Active elements such as switches or capacitors enable an antenna to change its operation frequency, radiation pattern or polarization by using different techniques $[4,5]$. This is a wireless system incorporating a reconfigurable antenna that is able to change its operation frequency, radiation pattern, and polarization, to cope with extendable and reconfigurable services, multiple standards, and multi-mode operations. Reconfigurable antennas can offer single or multiple reconfiguration features. However, the number of reconfigurable features is strongly dependent on the number of employed active elements and increasing as the number of switches increases [6,7]. 
To change antenna operation, switches like RF microelectromechanical systems (MEMS), varactor diodes, and PIN diodes, as well as the optically activated switches of fiber-optic cables, are being used [8-10]. Reconfigurable antennas with RF MEMS switches have a switching speed ranging from 1-200 $\mu \mathrm{sec}$. This is normally considered to be low for most applications [8]. An antenna combined with a varactor diode, the capacitance of which is controllable by a varying bias voltage, can have a wide tuning range. The design of the biasing network with varactor diodes has also been employed for the reconfigurable antenna design [9]. Hence, PIN diodes are preferred in reconfigurable antenna designs as they provide fast switching, and thus fast dynamic reconfiguration, with switching speeds ranging from 1-100 nsec [10]. In this paper, we present a comprehensive study of different types of reconfigurable antennas for mobile and wireless systems with simple or multiple reconfigurability functions. The paper is organized as follows: Section 2 discusses single reconfigurability in antennas. Different types of reconfigurable antennas with multiple reconfigurable features are studied in Section 3. Section 4 concludes the study.

\section{Antennas with a Single Reconfigure Feature}

Frequency switching, bandwidth switching, radiation pattern switching, and polarization switching are the different operations which can be performed by the reconfigurable antennas through changing the antenna size and shape of the radiators using active elements. In this section, different types of reconfigurable antennas with a single reconfigurable function are studied.

\subsection{Frequency-Reconfigurable Antennas}

Due to limited space available in modern wireless devices such as smartphones and tablets, the design of frequency-reconfigurable antennas requires much attention in terms of fundamental characteristics. These antennas can move dynamically from one frequency band to another or vary continuously in a range of frequencies [11-20]. They are mostly used in multi-band/multi-service systems requiring efficient reallocation of the dynamic spectrum: different types of switches are used. The most common method is to tune the electrical length of the antenna radiator using PIN diodes [11-13]. Varactor diode switches can tune the operation band in a wideband or ultra-wideband (UWB) mode and choose a desired narrowband mode [14,15]. Alternatively, the matching network has been used to set the resonance frequency $[16,17]$. Some other methods such as adding a shorting post on the antenna configuration or changing the input-impedance have been also proposed $[18,19]$. Hence, the antenna operational spectrum can be switched to the desired frequency in a variety of ways.

To help explain the theory of the frequency reconfigurable antenna, the configuration and performance of the antenna in [20] are represented in Figure 1. As illustrated, the antenna configuration is based on a composite right/left-handed transmission line (CRLH-TL), containing a shunt capacitance/inductance and series capacitance/inductance. The operation band of the antenna can be tuned by loading the varactor on the meander-line slot. The design exhibits frequency scanning in the range of $4.13-4.50 \mathrm{GHz}$ at $0-36 \mathrm{~V}$. The antenna provides very good frequency-reconfigurable characteristics and might be suitable for use in a phased array form for fifth generation (5G) base station applications. 


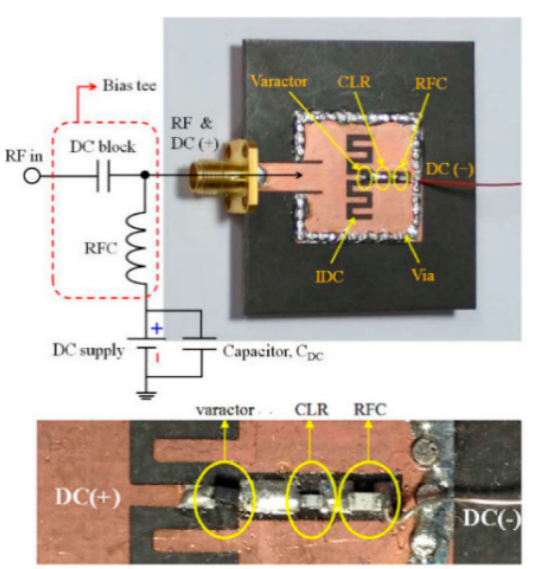

(a)

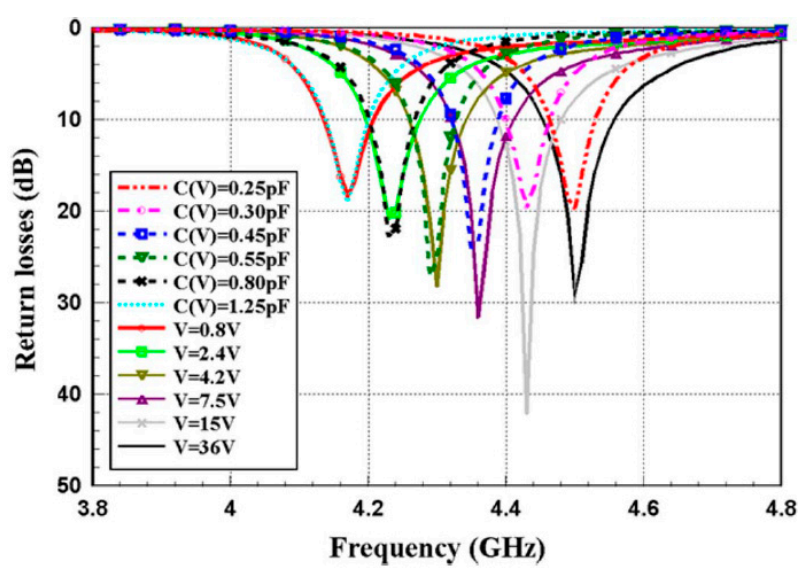

(b)

Figure 1. (a) Fabricated prototype of the reconfigurable antenna and (b) its frequency response for different voltage values [20]. Reproduced with permission from [20], Copyright IEEE, 2014.

\subsection{Bandwidth-Reconfigurable Antennas}

The operational bandwidth can also be changed from narrow-band to wide-band, which is usually achieved by employing a matching-network or reconfigurable-filter structure in the feed-line of the antenna [21-23]. The antenna must have good performance over the whole band of interest to cover both the narrow-band and wideband operating spectrums. Another method is to use a modified ground plane, especially for patch or monopole antennas. In [24], a bandwidth reconfigurable antenna was introduced for wireless local area network (WLAN) and worldwide interoperability for microwave access (WiMAX) applications.

The proposed antenna configuration is illustrated in Figure 2a. It has a rectangular radiation patch with a rotated F-shaped slot connected to a microstrip feed-line and a truncated ground plane in the back-side of an FR-4 substrate. A pair of PIN diodes in the middle of the slot on the radiation patch controls the current flow. By switching the operating states of the diodes, the frequency-bandwidth characteristic of the antenna can be reconfigured from narrow-band to wide-band, as illustrated in Figure $2 \mathrm{~b}$. The impedance bandwidth ranges from $22 \%$ to $78 \%$ which makes the antenna suitable for use in various wireless communication systems. In addition, the antenna can also have a reconfigurable characteristic to switch between a multi-resonance and wideband/UWB characteristic. This could be used to avoid interference between the UWB systems and other wireless systems such as fourth generation (4G), WLAN, WiMAX, and satellite communication systems [25]. This characteristic increases the flexibility of the antenna, combining different services in a single unit, suitable for multi-mode wireless communications.

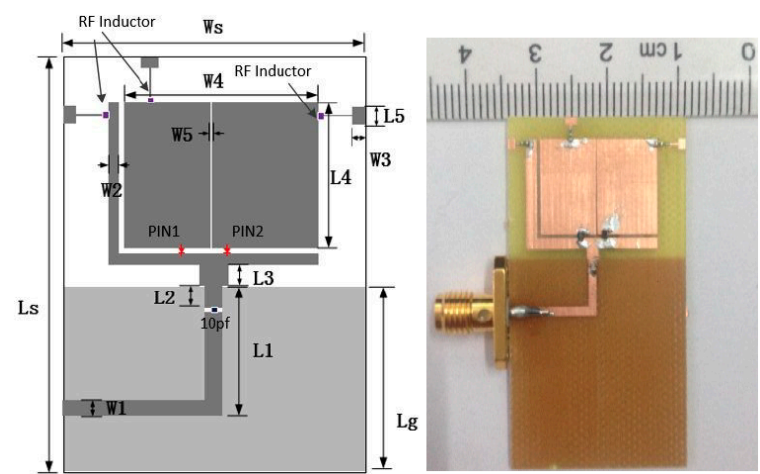

(a)

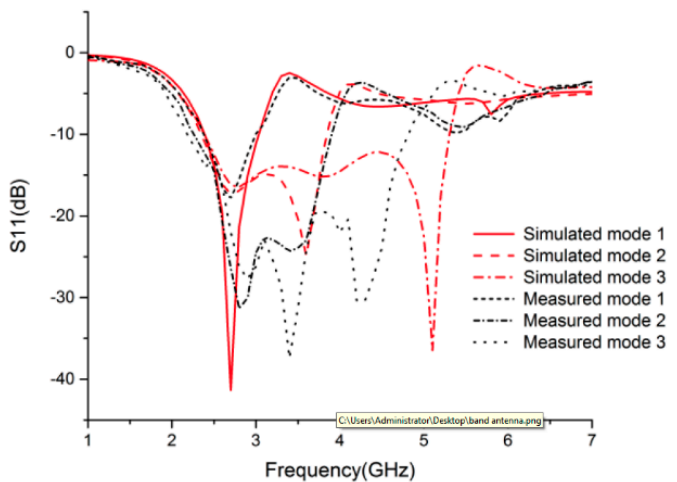

(b)

Figure 2. (a) Bandwidth-reconfigurable antenna configuration and (b) its performance for different states of the PIN diodes [24]. Reproduced with permission from [24], Copyright IEEE, 2016. 


\subsection{Pattern-Reconfigurable Antennas}

Pattern reconfigurable antennas are attractive in applications of surveillance and tracking because they produce radiation patterns with different directivities at the same operating frequency [26,27]. Commonly, either structures are designed with the potential to produce pattern diversity or the feeding configurations are reconfigurable, an application of array theory [28,29]. We shall discuss a typical example [30]. In Figure 3a, four identical arc dipoles along with reconfigurable feeding network are shown on different sides of a Rogers 4350B substrate. By changing the states of the diodes, the antenna end-fire radiation pattern can be steered with a 90-degree difference in the azimuthal plane to cover all directions, as illustrated in Figure $3 b$. The reflection coefficient $\left(S_{11}\right)$ characteristic of the antenna for the different conditions of the diodes is constant and covers the frequency range from 2.3-3.2 GHz of $4 \mathrm{G}$ and $5 \mathrm{G}$ operation bands.

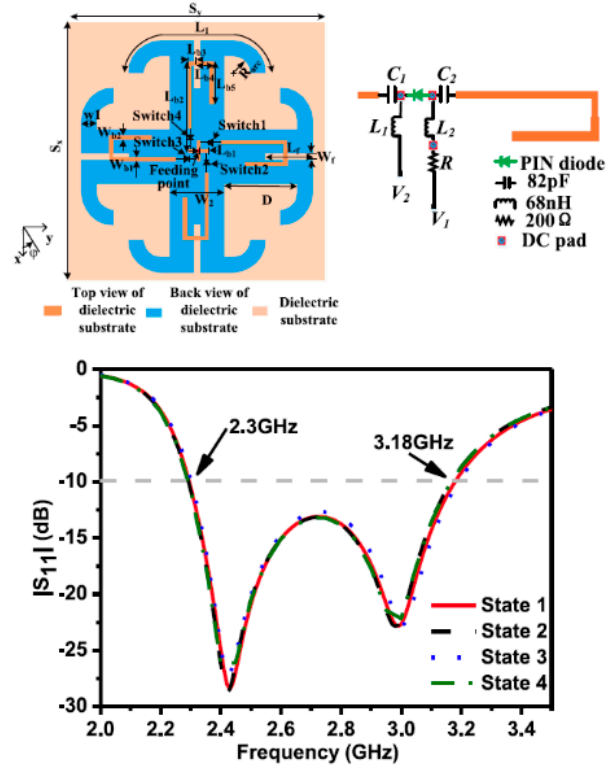

(a)

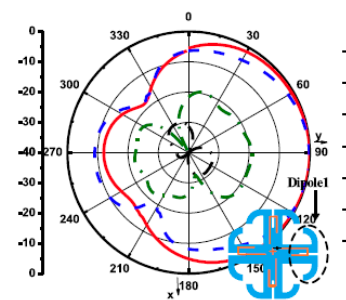

(a)

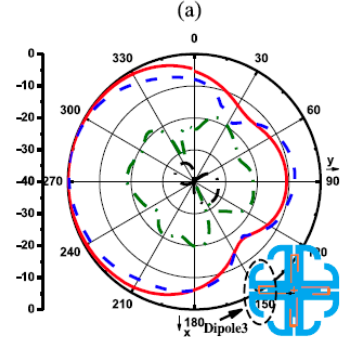

(c)

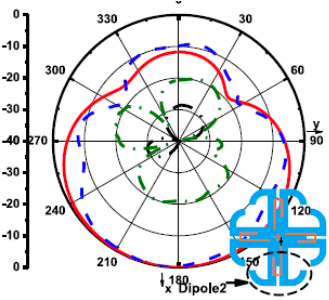

(b)

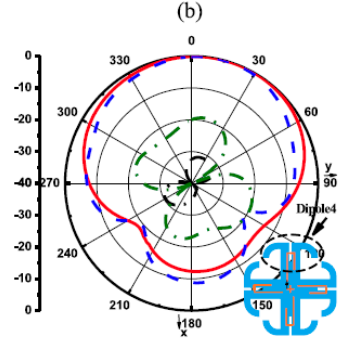

(d)

- Simulated co-pol Z. Measured co-pol
$=$ Measured x-pol

(b)

Figure 3. (a) Antenna configuration $S_{11}$ results and (b) the radiation patterns for different diode states [30]. Reproduced with permission from [30], Copyright IEEE, 2018.

Shorting pins, capacitor or reconfigurable ground structure to change the electric field distribution in the antenna substrate are used to change the direction of antenna radiation patterns [31-33]. In [34], a pattern reconfigurable phased array design was proposed for transmission angle sensing in $28 \mathrm{GHz}$ 5G mobile communication. The pattern reconfigurable antenna has been also used in multiple-input multiple-output (MIMO) wireless communications to reduce noise and improve system performance; a suitable example has been studied and its characteristics reported in [35].

\subsection{Polarization-Reconfigurable Antennas}

Antennas with polarization reconfigurability can offer exceptional multipath fading reduction. With this type, an antenna can be switched to different modes [36]. Most investigations in the polarization-reconfigurable antennas are concerned with switching between right-hand circular polarization (RHCP) and left-hand circular polarization (LHCP) at a desired frequency [37], although linear polarization (vertical or horizontal modes) is also studied [38,39]. Employing modified structures such as slot, slit, parasitic structures, and truncated corners of the main radiator along with embedded active elements are the most popular methods to obtain polarization-reconfigurability [40,41]. Adopting active structures such as meta-surfaces and feeding networks can also provide polarization 
reconfigurability [42]. Other techniques, such as using reconfigurable external polarizers or phase shifters, can also be useful [43].

In [44], a simple and new design of a polarization reconfigurable antenna with a C-shaped slot was introduced for 2.2-2.8 GHz 4G applications. Its configuration, shown in Figure 4a, consists of a circular radiation patch with a $\mathrm{C}$-shaped slot and two diodes across the concentric circular slot on the radiation patch. As can be observed from Figure $4 \mathrm{~b}$, the antenna can switch between vertical and horizontal linear polarizations (VP/HP) modes as well as between LHCP and RHCP circularly polarized modes, and is applicable for use in 5G wireless communications. In $[45,46]$, two designs of polarization reconfigurable patch antennas of compact size were reported for $5 \mathrm{G}$ wireless systems and their characteristics were investigated.

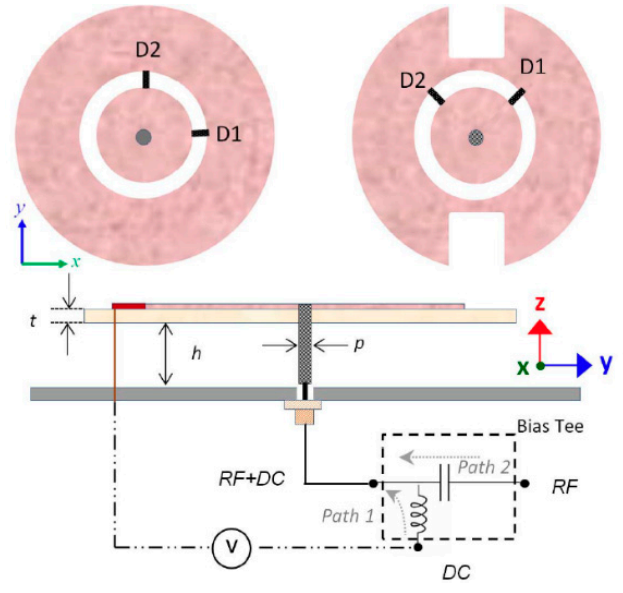

(a)
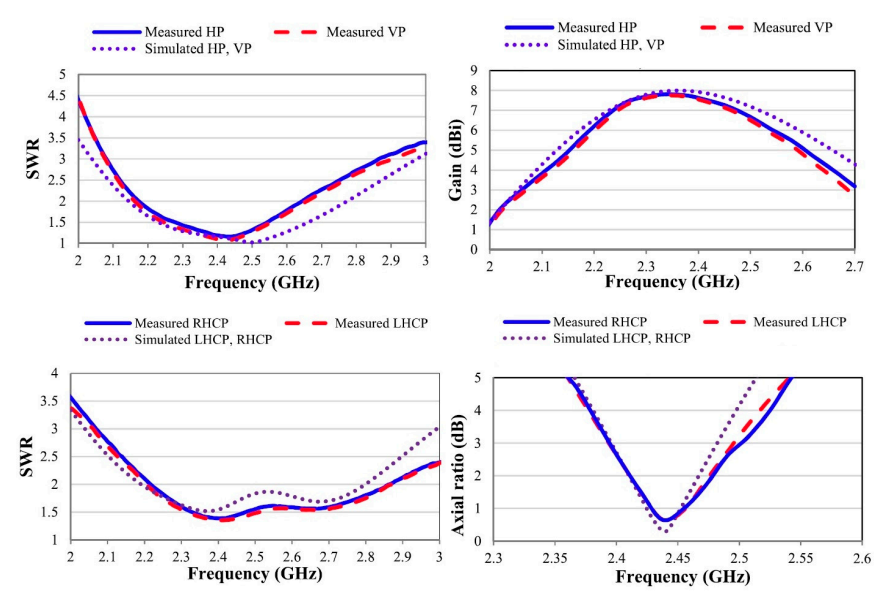

(b)

Figure 4. (a) Schematic and (b) standing wave ratio (SWR), gain, and axial ratio characteristics of the antenna [44]. Reproduced with permission from [44], Copyright IEEE, 2017.

\section{Multiple Reconfigurable Features in Antenna}

Multi-reconfigurable antennas can have two or more characteristics modified independently:

- frequency and bandwidth

- frequency and radiation pattern

- frequency and polarization

- radiation pattern and polarization

- frequency, radiation pattern, and polarization.

\subsection{Frequency and Bandwidth Reconfigurable Antennas}

There is an increasing demand in multi-service radios conforming to different spectrum standards for antennas switchable to single-band, multi-band, or wideband operation. This multi-function characteristic has become an important research area [47-55]. There are different antenna design methods which achieve this multimode function:

- to use a reconfigurable band-pass filter on the antenna feed-line to switch from narrow-band to wide-band operation [47-50].

- to use a modified ground plane with embedded parasitic and slit structures and also slots along with active elements such as PIN diodes [51-54].

- to combine different antennas which can give narrowband or wideband operation and could be used in cognitive-ratio (CR) or MIMO mobile communications [55].

Some examples are described below. 
In [47-50], the main idea proposed was to integrate a switchable filtering element on the feed-line of a broadband antenna. In [47], a circular disc microstrip-fed monopole antenna with wideband to narrowband frequency reconfiguration was introduced. As shown in Figure 5a, the antenna was integrated with a reconfigurable band-pass filter in the feed-line. The impedance bandwidth could be reconfigured from wideband to narrowband using an active element, as illustrated in Figure $5 b$. For the narrowband state, a pair of varactor diodes has been used to tune the antenna response from 3.9 to $4.7 \mathrm{GHz}$ with constant isolation. In [48], an elliptical monopole antenna with a rectangular slot in the partial ground plane was developed. The configuration of the antenna is composed of four resonators coupled to the split transmission line at the center along with the integrated reconfigurable band-pass filter (BPF) element onto the $50 \Omega$ feed-line. The frequency performance of the antenna can be switched to operate at $1.8 \mathrm{GHz}, 2.4 \mathrm{GHz}, 3.5 \mathrm{GHz}$ (WiMAX/5G), and 5.2 GHz (WLAN), using four PIN diodes to switch between bands. With all diodes in their OFF state, the antenna provides wide bandwidth cover of all the four bands. In [49], a new narrow-band antenna into a large ultra-wideband antenna was proposed. Its configurationis the integration of an UWB monopole antenna printed on the top layer and a reconfigurable feeding structure printed on the bottom layer of the substrate. The antenna not only exhibits UWB impedance bandwidth but also could be tuned between six narrow bands, thus the slot antenna with its reconfigurable feeding structure makes the antenna suitable for CR applications.
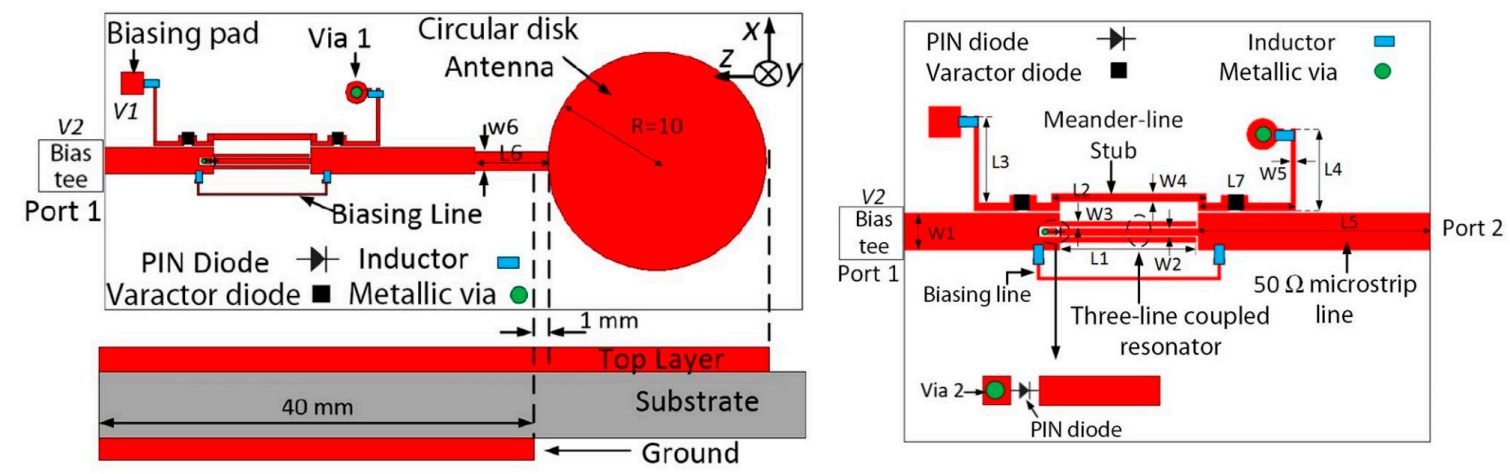

(a)
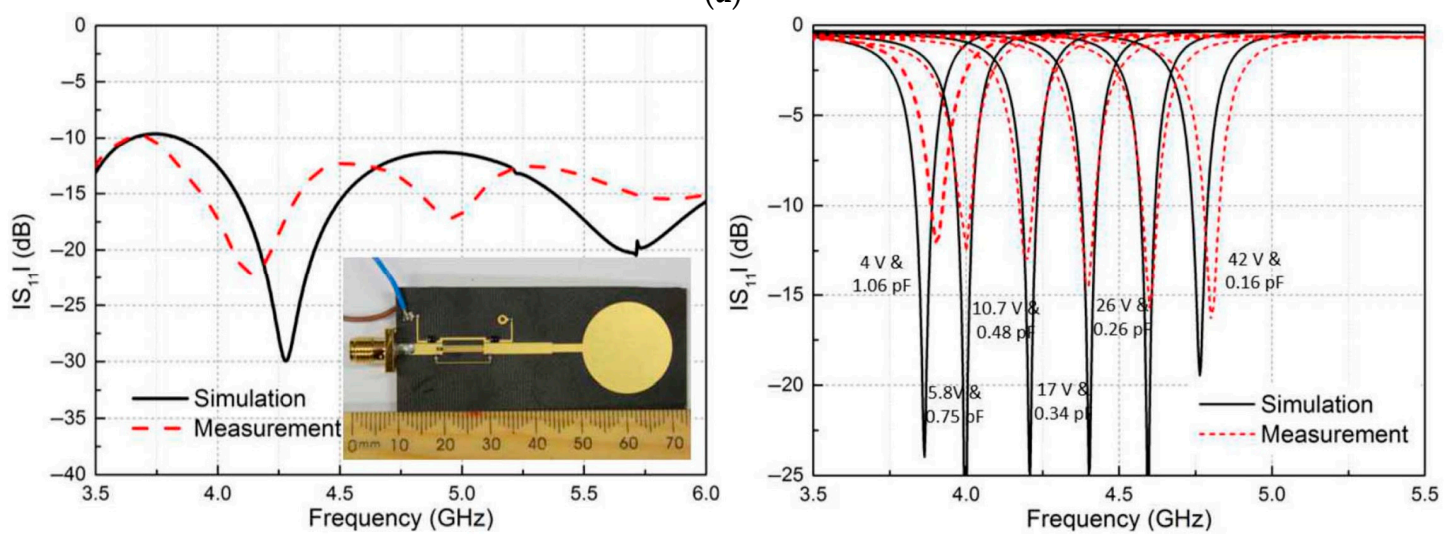

(b)

Figure 5. (a) Configuration and (b) performance of the frequency and bandwidth reconfigurable antenna in [47]. Reproduced with permission from [47], Copyright IEEE, 2015.

Another similar design was proposed in [50]. It is a microstrip-fed antenna including two resonators coupled to the feed-line. The basic antenna has UWB performance while each resonator can provide one narrowband, with the bi-bands mode achieved by activating both resonators at the same time. In [51,52], two designs of integrated reconfigurable MIMO antennas for 3G/4G/5G mobile terminals was presented: an UWB sensing antenna are integrated with reconfigurable MIMO antennas 
on the same substrate. In the antenna cited in [51], a pair of reconfigurable antennas with meander-line configuration, is employed on the top layer of the board. The UWB antenna on the reverse of the substrate acts as a ground plane for the reconfigurable elements. The UWB antenna exhibits a broad bandwidth of 720-3440 MHz, while the reconfigurable MIMO element can switch between different frequencies in the 573-2550 MHz range. The reconfigurable MIMO element in [52] contained modified printed inverted-F antenna (PIFA) antennas each with their digital biasing circuitry. The switching mechanism of the antenna contained four PIN diodes leading to four distinct modes between 755 and $3450 \mathrm{MHz}$.

In $[53,54]$, single-port wide to narrowband monopole antennas with uni-planar configurations were proposed. Switching between the wideband and narrow communication bands was obtained using two PIN diodes in a ring-slot filter design in the feed-line. The proposed antenna in [53] exhibited wide-to-narrow band reconfiguration from 1.6-6.0 GHz (UWB) to 3.39-3.80 GHz (5G). A pair of varactor diodes tunes the narrowband operation from $2.55-3.2 \mathrm{GHz}$ [54]. The wideband state provides around $5 \mathrm{GHz}$ bandwidth (1.35-6.2 GHz). For a new combined antenna system containing an UWB antenna for spectrum sensing and a dipole antenna narrowband, communication was proposed in [55], using two feeding ports to obtain wideband coverage of $2-5.5 \mathrm{GHz}$ and narrow-band resonance at $2.8 \mathrm{GHz}$. The system can cover the spectra of IEEE 802.11ac and 802.11n, universal mobile telecommunications service (UMTS) 2000, and 4G/5G mobile terminals and is suitable for use in front-end CR applications.

\subsection{Frequency and Radiation-Pattern Reconfigurable Antennas}

In this category, operation frequency or radiation pattern characteristics can be reconfigured [56]. The antenna radiation pattern can also be reconfigured between broad-side, end-fire, and omni-directional modes [57]; radiation pattern reconfiguration can enhance system performance, suppress noise, and save energy by improving signal directions. Frequency tuning is very useful to suppress interference from other wireless systems and also to reduce the number of the antennas required [58]. Due to this, a great number of antenna designs of this type have been reported [59-67]. The usual method in most designs is to switch the frequency operation of the antenna by using active elements, namely varactors or PIN diodes [59-63]. Pattern reconfiguration can be achieved using a modified ground plane with slot or slit structures to change the current distribution of the antenna substrate in order to steer the direction of the antenna radiation pattern $[64,65]$, or can use switchable directors at different sides of the main antenna radiator $[66,67]$.

In [58], a patch antenna design with dual-pattern frequency-reconfigurable characteristics was proposed. The antenna provides radiation patterns with monopolar and broadside modes and its frequency band can be switched using four varactors. A single-fed double-element array design with frequency and radiation pattern reconfigurability was introduced in [59]. The frequency operation of the antenna is tunable between $2.15-2.38 \mathrm{GHz}$. Beam scanning between $\pm 23^{\circ}$ was obtained using a tuning mechanism. Another frequency and pattern reconfigurable antenna with combined monopole and patch antennas was proposed in [60]. A microstrip-fed patch to resonate at a lower frequency is printed on the upper layer and the monopole to operate at a higher frequency is placed in the bottom ground of a Rogers RO4350 substrate. Five PIN diodes, divided into group $A\left(D_{1}, D_{2}\right.$, and $\left.D_{3}\right)$ and group $\mathrm{B}\left(\mathrm{D}_{4}\right.$ and $\left.\mathrm{D}_{5}\right)$, were employed. By changing the states of these two groups, the antenna can be switched into different modes. With group $\mathrm{A} O \mathrm{ON}$, the antenna acts as an omnidirectional monopole radiator operating at $2.4 \mathrm{GHz}$. When group $\mathrm{B}$ is $\mathrm{ON}$, the design performs as a broad-side patch antenna working at $5.5 \mathrm{GHz}$. Having both groups OFF, the monopole mode and patch mode are active.

In [61], a reconfigurable slot antenna with a modified ground plane was reported. Two rectangular slots with six PIN diodes in the ground plane provide frequency reconfiguration with different radiation modes. The antenna can operate at eleven different frequencies of $S$ and $C$ band in the frequency range of 2.2-6.5 GHz. A wideband reconfigurable slot antenna for long-term evolution (4G-LTE) and C-band applications was presented in [62]. Its design contains a pair of symmetric slots fed by a fork-shaped feed-line. Pairs of PIN diodes $\left(\mathrm{D}_{1}\right.$ and $\mathrm{D}_{2}$ and $\mathrm{D}_{3}$ and $\left.\mathrm{D}_{4}\right)$ are loaded in the slots 
and feed line to produce frequency and radiation pattern reconfiguration, respectively. Another design of a slot antenna with frequency and pattern reconfigurable properties was introduced in [63], where the antenna, fed by a coaxial port, is composed of four slits with three switches for tuning the scanning angle between $\pm 15^{\circ}$. Two switches placed in the main slot radiator tune between three different narrow bands at $1.82 \mathrm{GHz}, 1.93 \mathrm{GHz}$, and 2.10 GHz. BAR50-02V PIN diodes were used as switches. A flexible frequency and radiation pattern antenna design was proposed in [64]. Its schematic contains two symmetric hexagonal split rings with monopole branches and eight PIN diodes. By changing the diode states, the antenna frequency can switch between $1.9-2.4 \mathrm{GHz}$ with pattern steering capability in two directions.

In [65], a back-to-back F (BTBF) semi-circular antenna was presented (see Figure 6a), composed of a patch radiator with four identical elements. Depending on the states of the embedded diodes, the antenna can work at three different frequency bands. Another design of antenna with frequency and radiation pattern selectivity, shown in Figure 6b, was introduced in [66]; it is enclosed in a circular area, with six symmetrical main radiators and twelve parasitic elements. Three circular slots are etched in a circular ground patch placed on the midline of the microstrip feed line. By changing the diode states, the antenna can operate at the frequency bands of wireless broadband (Wibro), WLAN, Zigbee, and satellite-digital multimedia broadcasting (S-DMB) communications with the capability of steering the antenna radiation pattern to six different angles in each frequency band. In addition, since six radiation elements were used in the design, the antenna pattern can be steered to different angles in $45^{\circ}$ steps to provide full coverage.
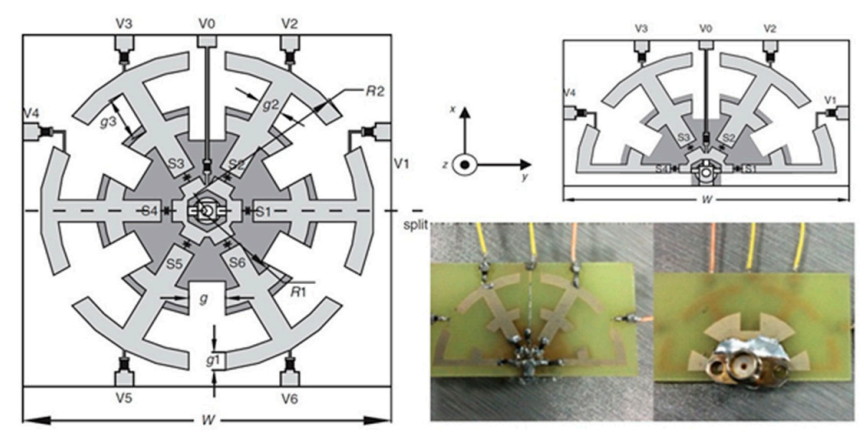

(a)

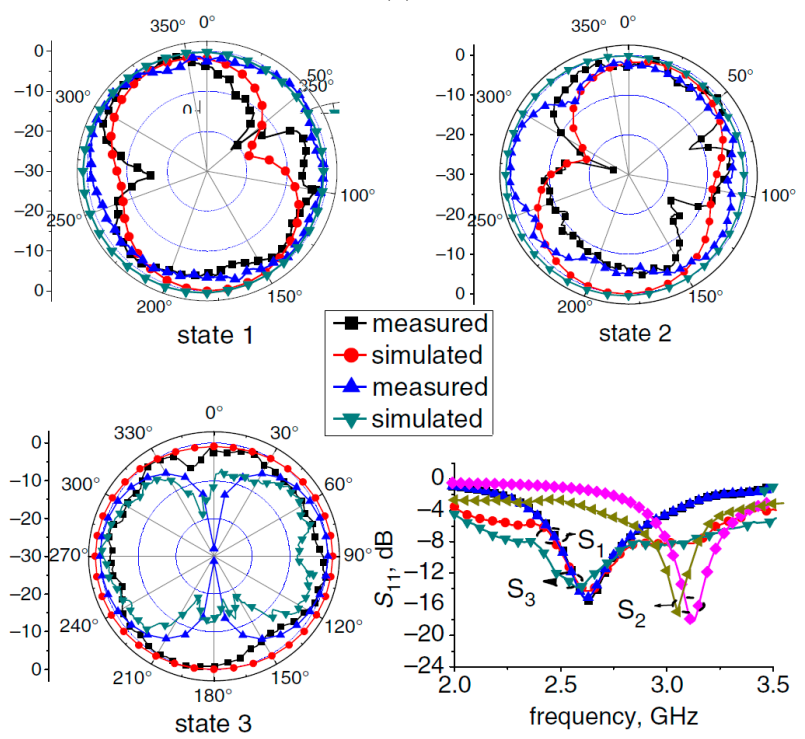

(b)

Figure 6. (a) Configuration and (b) performance of the frequency and pattern reconfigurable antenna in [65]. Reproduced with permission from [65], Copyright IEEE, 2015. 
Reference [67] proposed a dipole driven element with calculated pixilation and a pair of parasitic elements to provide frequency and pattern switching. The antenna has modes at $900 \mathrm{MHz}, 1800 \mathrm{MHz}$, or $2.1 \mathrm{GHz}$, with directional or omnidirectional radiation patterns. In [68], a novel planar antenna containing dual symmetrical radiators with rectangle parasitic elements and an inverted T-shape ground plane was proposed. By loading the parasitic elements and choosing different radiators for the feeding, the antenna can operate at three different frequencies with two different kinds of radiating pattern.

\subsection{Frequency and Polarization Reconfigurable Antennas}

An antenna of this type is very useful in imaging, sensing, tracking and radar applications [69]. With frequency reconfiguration, the antenna system is able to tune and make use of the available spectrum. Polarization diversity can reduce the effects of multipath and enhance channel capacity. There is a growing interest in using this type of reconfiguration combination and a number of designs have been proposed [70]. One important method makes use of an active electromagnetic band gap (EBG) or metasurface structure along with switches on top of the antenna resonator [69-72]. However, most common is the integration of methods for achieving frequency and polarization reconfigurability using active elements such as varactor diodes and PIN diodes, in addition to some other modifications [73-76]. Different antennas with frequency and polarization reconfigurable functions are reviewed below.

Two such designs were introduced in [69,70]. The configuration of the EBG in [69] composed of rectangular patch arrays on both sides of the substrate. A coplanar waveguide (CPW)-fed monopole antenna with wide bandwidth was placed above the designed EBG surface. By tuning the employed varactors in the EBG structure, the antenna can generate circular polarization at different frequencies from 1.1-1.7 GHz, and can be switched between LHCP and RHCP. For the design proposed in [70], the main radiator is a dipole antenna which can work at four different states, thanks to the reconfigurable EBG structure. By changing the diode states, the antenna frequency can be switched between 4.4-4.6 GHz. The polarization can be dynamically tuned for RHCP, LHCP, and LP.

Another design was introduced in [71]. Its structure consists of a planar slot antenna as the main radiator, and a metallic reflector with a metasurface. By adjusting the positions between the center of the slot radiator and the metasurface, frequencies from $8.0-11.2 \mathrm{GHz}$ and polarization states LP, LHCP, and RHCP could be chosen. A square ring antenna patch antenna with two horizontal gaps [72] provided LP at 2.4 and $4.18 \mathrm{GHz}$, and LHPC and RHCP characteristics at $3.4 \mathrm{GHz}$. A square-ring patch radiator cut in the ground plane has a vertical gap across which two PIN diodes bridge. A stub-loaded reconfigurable patch antenna with frequency and polarization agility was proposed in [73]; see Figure 7a. Twelve loading stubs are sited at the four edges of the main radiator. As illustrated in Figure $7 \mathrm{~b}$, the frequency can be tuned from 2.4-3.4 GHz with diverse polarization, and so the antenna is suitable for multi-mode $4 \mathrm{G} / 5 \mathrm{G}$ communication systems.

A simple monopole antenna with different states of frequency and polarization diversity was introduced in [74]. It includes a monopole radiator, a reflector, and a modified ground plane with two slots. A pair of switches reconfigures the antenna, allowing four states covering $2.02-2.56 \mathrm{GHz}$, $2.32-2.95 \mathrm{GHz}, 1.92-2.70 \mathrm{GHz}$, and $1.88-2.67 \mathrm{GHz}$. The radiation is linearly polarized in states 1 and 2, and LHCP and RHCP in states 3 and 4 . Another patch antenna design with a corner segment providing frequency/polarization diversity was presented in [75]. A PIN diode between the patch radiator and the embedded corner segment switches the frequency between $5.6-5.8 \mathrm{GHz}$ and the polarization between LHCP and RHCP. In [76], a reconfigurable patch antenna design with dual-probe coupler feed network was presented. The proposed antenna has two layers and an active element (varactor diode) installed between the inner and outer patch on the top layer. Polarization diversity is achieved using the probe feed network. Furthermore, the antenna can tune its operation frequency from $2.05-3.13 \mathrm{GHz}$ by variation of the varactor diode capacitance between $12.33-1.30 \mathrm{pF}$. 

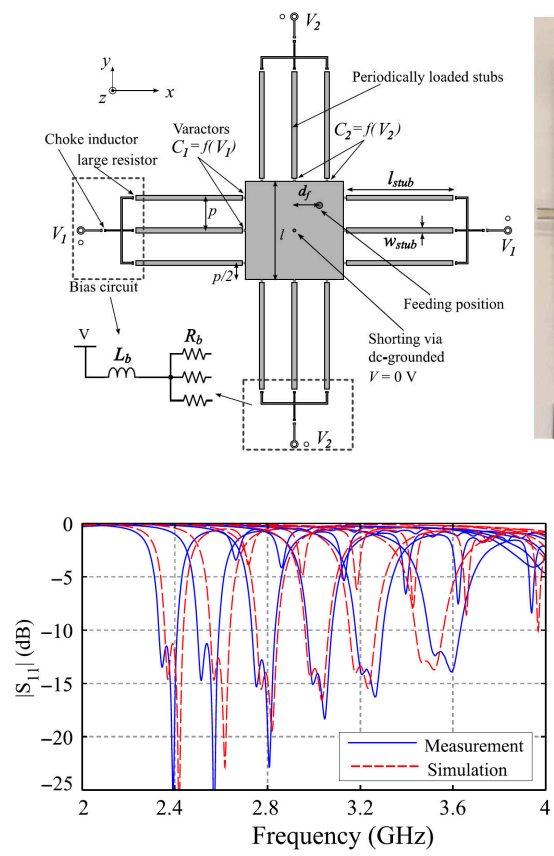
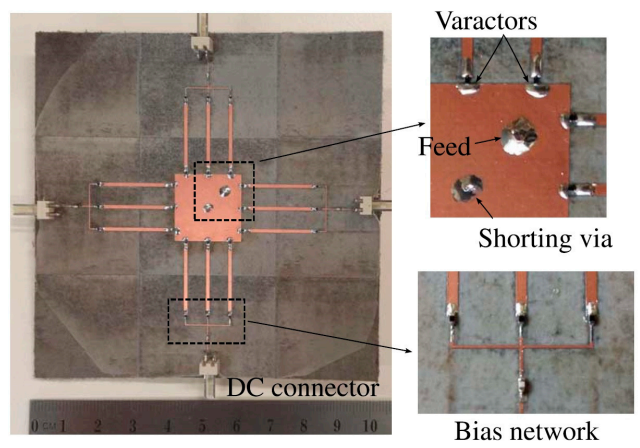

(a)

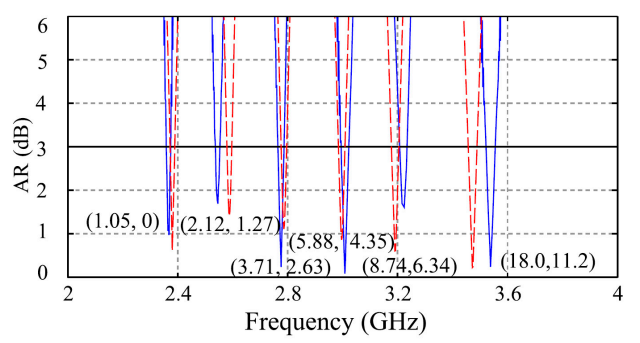

(b)

Figure 7. (a) Configuration and (b) performance of the frequency and polarization reconfigurable antenna in [73]. Reproduced with permission from [73], Copyright IEEE, 2015.

\subsection{Radiation Pattern and Polarization Reconfigurable Antennas}

Radiation pattern and polarization reconfigurable antennas offer benefits such as providing pattern diversity and supporting different polarizations on a single element antenna radiator [77]. They also can improve the capacity of communication systems, increase signal power, improve radiation coverage, and avoid polarization mismatching. Radiation pattern reconfigurability can steer the antenna pattern to satisfy system needs [78], and can improve channel capacity without increasing a radiator's volume [79,80]. Many such antennas have been proposed recently [77-84].

An omnidirectional microstrip-fed patch antenna with a switchable polarization and radiation pattern was introduced in [77]. A pair of back-to-back coupled patches fed at a corner, and a shared ground plane. A phase shifting technique provides a high degree of polarization and radiation pattern reconfigurability. An antenna with switchable radiation patterns and polarization diversity was proposed in [78]. The design concept is to place reconfigurable parasitic elements around the main radiator. Each parasitic element includes a dipole radiator with a PIN diode, whereby the radiation pattern can be switched into different directions by changing the diode states. Furthermore, the antenna can be dynamically reconfigured into three different polarizations. In [79], a PIFA was proposed with radiation pattern and polarization diversity; the main radiator has an inverted F-shaped parasitic structure. Using only one diode, the antenna can switch the antenna pattern and polarization properties in the frequency range of 2.357-2.562 GHz. In [80], a reconfigurable antenna design with switchable radiation pattern and polarization diversity for the band of $2.45-2.65 \mathrm{GHz}$ was introduced. The antenna includes three circular substrate disks for radiator, feeding and switching along with four plastic screws to support the substrates, with an annular slot structure etched in the circular patch radiator. The reconfigurable feed network with one input and four output ports and with L-shaped feeding probes are placed in the middle layer which includes three power dividers. The antenna can provide switchable radiation beams for broadside and conical circular polarized modes.

In [81], a design of a reconfigurable antenna with a metasurface structure was proposed. The overall structure has three layers. The metasurface, to improve the antenna gain, was on the top layer, with the ground plane and the microstrip feed-line on the middle and bottom layers respectively. The antenna is designed to work at $5 \mathrm{GHz}$, with switchable polarization using the PIN 
diodes in the ground plane. In addition, the antenna radiation pattern can be steered between $\pm 20^{\circ}$ by controlling the PIN switched in the metasurface. A $0.9 \mathrm{GHz}$ reconfigurable quadrifilar helical antenna with a switchable feeding network was proposed in [82]. Figure 8 shows the cuboid radiator, reconfigurable feeding-network, biasing network, and the fabricated prototype. By switching the diode states, the antenna can provide four different modes with polarization and radiation pattern reconfiguration. It has a low profile and provides wide bandwidth with broad axial ratio characteristics and LHCP/RHCP. Another pattern and polarization reconfigurable antenna was presented in [83]. The radiator is a square patch with four coupled parasitic structures fed by a coaxial cable. Using PIN diodes, the antenna provides three different modes for polarization and pattern diversity at one frequency. A multi-layer wideband reconfigurable circular polarized $(\mathrm{CP})$ antenna with four radiating arms was proposed in [84]. The radiating arms are connected to a reconfigurable feeding network with PIN diodes to provide wideband CP waves in RHCP and LHCP modes. The radiation pattern can be switched from bidirectional to broadside modes and the antenna's placement above a metallic reflector improves its gain. The frequency range is $1.00-2.25 \mathrm{GHz}$ with an axial ratio bandwidth of 1.5-1.9 GHz, thus suitable for global positioning system (GPS), radio-frequency identification (RFID), and mobile communications.

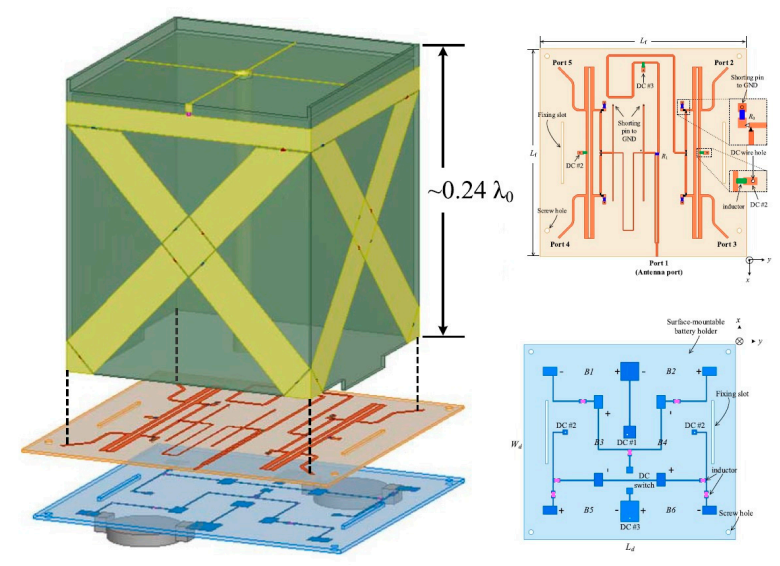

(a)

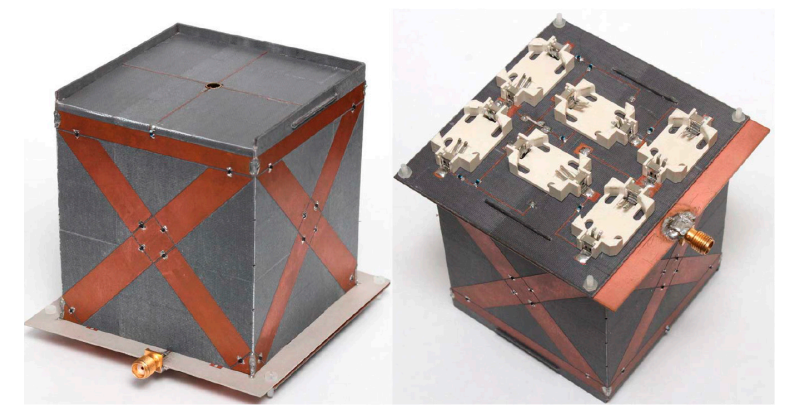

(b)

Figure 8. The configurations of the (a) designed and (b) fabricated pattern and polarization reconfigurable antenna [82]. Reproduced with permission from [82], Copyright IEEE, 2018.

\subsection{Frequency, Radiation Pattern, and Polarization Reconfigurable Antennas}

None of the above designs provide more than one or two reconfigurable features. In the literature there is only one design, proposed in [85], for independently three-parameter reconfiguration. In [86], another design of frequency, radiation pattern, and polarization reconfigurable antenna was proposed, but with limitations in terms of tuning, and, unlike the design in [85], it cannot provide simultaneous, independent reconfiguration. This is a major research gap, albeit a much harder challenge to design an antenna with the flexibility to reconfigure all its fundamental properties in terms of frequency, radiation pattern, and polarization. In the following, the design of [85] is explored. 
Figure 9 shows the antenna schematics and the prototype [85], a patch antenna radiator and a parasitic pixel surface with 66 pixels and 60 PIN diodes. It is the switched-grid pixel surface that enables the antenna to be reconfigured simultaneously in frequency, radiation pattern, and polarization. Different configurations of the switches tune the frequency of operation from 2.4-3 GHz. The antenna radiation pattern can be steered between $\pm 30^{\circ}$, and its polarization can be reconfigured between LHCP/RHCP and LP. The design is suitable for different mobile and wireless communication systems.

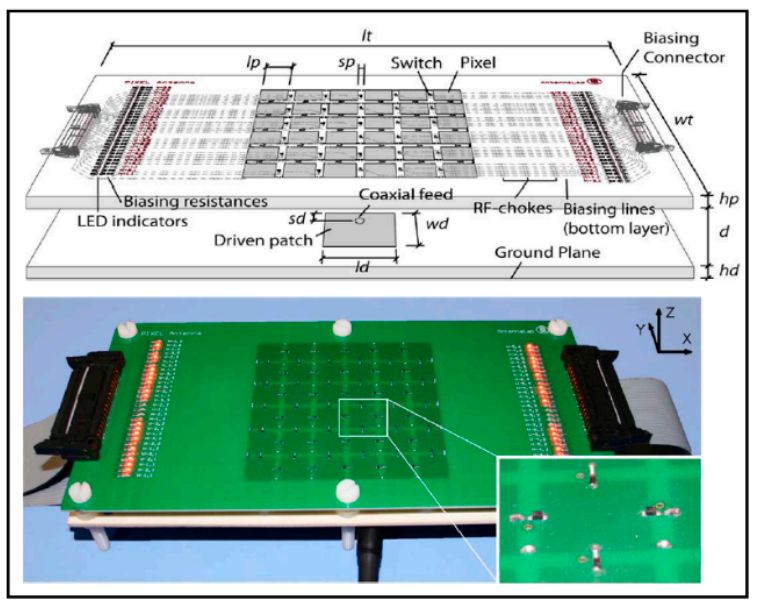

Figure 9. Schematic of the multi-functional reconfigurable antenna [85]. Reproduced with permission from [85], Copyright IEEE, 2014.

Table 1 provides a comparative summary of recently proposed reconfigurable antenna types published in the literature. Fundamental characteristics in terms of antenna type, reconfiguration type and the number of the employed switches, operation frequency, and the overall size of the antennas are provided and have been compared. This is intended to help readers to determine what types of reconfigurable antennas are most suitable for their applications.

Table 1. Comparative summary of reconfigurable antennas described in the literature.

\begin{tabular}{|c|c|c|c|c|c|c|}
\hline References & $\begin{array}{l}\text { Antenna } \\
\text { Type }\end{array}$ & $\begin{array}{c}\text { Reconfiguration } \\
\text { Type }\end{array}$ & $\begin{array}{c}\text { Reconfiguration } \\
\text { Means }\end{array}$ & $\begin{array}{l}\text { Frequency } \\
(\mathrm{GHz})\end{array}$ & $\begin{array}{c}\text { No. of } \\
\text { Switches }\end{array}$ & $\begin{array}{c}\text { Antenna } \\
\text { Size (mm) }\end{array}$ \\
\hline [14] & Monopole & Frequency & PIN-Diode & $1.77-2.51$ & 4 & $50 \times 120$ \\
\hline [21] & Patch & Bandwidth & PIN-D/MEMS & $2-4$ & 8 & $12 \times 12$ \\
\hline [23] & Slot & Bandwidth & PIN-Diode & $1.64-2.68$ & 6 & $10 \times 64$ \\
\hline [31] & DRA & Rad. Pattern & PIN-Diode & 5.8 & 8 & $50 \times 50$ \\
\hline [40] & Patch & Polarization & PIN-Diode & $2.1-2.6$ & 24 & $60 \times 60$ \\
\hline [48] & Monopole & $\mathrm{F} / \mathrm{B}$ & PIN/varactor & $3.9-4.82$ & 3 & $25 \times 75$ \\
\hline [52] & Monopole & $\mathrm{F} / \mathrm{B}$ & PIN/varactor & $0.72-3.44$ & 4 & $65 \times 120$ \\
\hline [53] & Monopole & $\mathrm{F} / \mathrm{B}$ & PIN-Diode & $3.4-8 / 4.7-5.4$ & 4 & $70 \times 70$ \\
\hline [59] & Patch & $\mathrm{F} / \mathrm{R}$ & varactor Diode & $2.15 / 2.25 / 2.38$ & 2 & $151.5 \times 160.9$ \\
\hline [74] & Monopole & $\mathrm{F} / \mathrm{P}$ & PIN-Diode & $1.9-2.7$ & 2 & $40 \times 70$ \\
\hline [76] & Patch & $\mathrm{F} / \mathrm{P}$ & varactor Diode & $2-3.1$ & 1 & $100 \times 100$ \\
\hline [79] & PIFA & $\mathrm{R} / \mathrm{P}$ & PIN-Diode & 2.5 & 1 & $50 \times 50$ \\
\hline [81] & Slot & $\mathrm{R} / \mathrm{P}$ & PIN-Diode & 5 & 36 & $78 \times 78$ \\
\hline [82] & Helical & $\mathrm{R} / \mathrm{P}$ & PIN-Diode & 0.9 & 32 & $81 \times 81$ \\
\hline [85] & Patch & $\mathrm{F} / \mathrm{R} / \mathrm{P}$ & PIN-Diode & $2.4-3$ & 60 & $31 \times 31$ \\
\hline
\end{tabular}




\section{Conclusions}

In this paper, an exhaustive review of reconfigurable antennas with single and multiple reconfiguration features has been presented, classifying the various types of reconfigurable antenna. Several design techniques are discussed in detail with examples, and the fundamental properties of different reconfigurable antenna types are set out. That the complexity of an antenna increases with the number of reconfigurable parameters is clearly stressed in this review. In addition, the presentation highlights a design requirement: the ability to design an antenna with simultaneous and independently flexible reconfigurations of antenna frequency, radiation patterns, and polarization characteristics is not yet achieved, and needs more research and investigation.

Author Contributions: Conceptualization, N.O.P. and H.J.B.; methodology, N.O.P. and H.J.B.; software, N.O.P. and H.J.B.; validation, N.O.P., H.J.B., Y.I.A.A.-Y., R.A.A.-A., and A.M.A.; formal analysis, N.O.P., H.J.B., Y.I.A.A.-Y., R.A.A.-A., and A.M.A.; investigation, N.O.P., H.J.B., and R.A.A.-A.; resources, N.O.P., H.J.B., and R.A.A.-A.; data curation, N.O.P., H.J.B., and R.A.A.-A.; writing-original draft preparation, N.O.P., H.J.B., and J.M.N.; writing—review and editing, N.O.P., H.J.B., R.A.A.-A., and J.M.N.; visualization, N.O.P., R.A.A.-A., and J.M.N.

Funding: This project has received funding from the European Union's Horizon 2020 research and innovation programme under grant agreement H2020-MSCA-ITN-2016 SECRET-722424.

Acknowledgments: Authors wish to express their thanks to the support provided by the innovation programme under grant agreement H2020-MSCA-ITN-2016 SECRET-722424.

Conflicts of Interest: The authors declare no conflict of interest.

\section{References}

1. Nadeem, Q.-U.-A.; Kammoun, A.; Debbah, M.; Alouini, M.-S. Design of 5G full dimension massive MIMO systems. IEEE Trans. Commun. 2018, 66, 726-740. [CrossRef]

2. Bhartia, P.; Bahl, I.J. Frequency agile microstrip antennas. Microw. J. 1982, 25, 67-70.

3. Bernhard, J.T. Reconfigurable Antennas; Morgan \& Claypool Publishers: San Rafael, CA, USA, 2007.

4. Peroulis, D.; Sarabandi, K.; Kateh, L.P.B. Design of reconfigurable slot antennas. IEEE Trans. Antennas Propag. 2005, 53, 645-654. [CrossRef]

5. Christodoulou, C.G.; Tawk, Y.; Lane, S.A.; Erwin, S.R. Reconfigurable antennas for wireless and space applications. Proc. IEEE. 2012, 100, 2250-2261. [CrossRef]

6. Balanis, C.A. Antenna Theory Analysis and Design, 4th ed.; John Wiley \& Sons: New York, NY, USA, 1998.

7. Bernhard, J.T. Reconfigurable Antennas; Wiley: New York, NY, USA, 2005.

8. Grau, J.R.; Lee, M.J. A dual-linearly-polarized MEMS-reconfigurable antenna for NB MIMO communication systems. IEEE Trans. Antennas Propag. 2010, 58, 4-17. [CrossRef]

9. Tawk, Y.; Costantine, J.; Christodoulou, C.G. A varactor based reconfigurable filtenna. IEEE Antennas Wirel. Propag. Lett. 2012, 11, 716-719. [CrossRef]

10. Nikolaou, S.; Bairavasubramanian, R.; Lugo, C.; Carrasquillo, I.; Thompson, D.C. Pattern and frequency reconfigurable annular slot antenna using PIN diodes. IEEE Trans. Antennas Propag. 2006, 54, 439-448. [CrossRef]

11. Parchin, N.O.; Al-Yasir, Y.; Abdulkhaleq, A.M.; Elfergani, I.; Rayit, A.; Noras, J.M.; Rodriguez, J.; Abd-Alhameed, R.A. Frequency reconfigurable antenna array for mm-Wave 5G mobile handsets. In Proceedings of the 9th International Conference on Broadband Communications, Networks, and Systems, Faro, Portugal, 19-20 September 2018.

12. Ojaroudi, N.; Parchin, N.O.; Ojaroudi, Y.; Ojaroudi, S. Frequency reconfigurable monopole antenna for multimode wireless communications. Appl. Comput. Electromagn. Soc. J. 2014, 8, 655-660.

13. Ojaroudi, N.; Ghadimi, N.; Ojaroudi, Y.; Ojaroudi, S. A novel design of microstrip antenna with reconfigurable band rejection for cognitive radio applications. Microw. Opt. Technol. Lett. 2014, 56, 2998-3003. [CrossRef]

14. Hussain, R.; Sharawi, M.S.; Shamim, A. An integrated four-element slot-based MIMO and a UWB sensing antenna system for CR platforms. IEEE Trans. Antennas Propag. 2018, 66, 978-983. [CrossRef]

15. Hussain, R.; Khan, M.U.; Sharawi, M.S. An integrated dual MIMO antenna system with dual-function GND-plane frequency-agile antenna. IEEE Antennas Wirel. Propag. Lett. 2018. [CrossRef] 
16. Hinsz, L.; Braaten, B.D. A frequency reconfigurable transmitter antenna with autonomous switching capabilities. IEEE Trans. Antennas Propag. 2014, 62, 3809-3813. [CrossRef]

17. Hannula, J.-M.; Saarinen, T.; Holopainen, J.; Viikari, V. Frequency reconfigurable multiband handset antenna based on a multichannel transceiver. IEEE Trans. Antennas Propag. 2017. [CrossRef]

18. Nguyen-Trong, N.; Piotrowski, A.; Fumeaux, C. A frequency reconfigurable dual-band low-profile monopolar antenna. IEEE Trans. Antennas Propag. 2017, 65, 3336-3343. [CrossRef]

19. Boukarkar, A.; Lin, X.Q.; Jiang, Y.; Chen, Y.J.; Nie, L.Y.; Mei, P. Compact mechanically frequency and pattern reconfigurable patch antenna. IET Microw. Antennas Propag. 2018, 12, 1864-1869. [CrossRef]

20. Sam, S.; Kang, H.; Lim, S. Frequency reconfigurable and miniaturized substrate integrated waveguide interdigital capacitor (SIW-IDC) antenna. IEEE Trans. Antennas Propag. 2014, 62, 1039-1045. [CrossRef]

21. Anand, S.; Raj, R.K.; Sinha, S.; Upadhyay, D.; Mishra, G.K. Bandwidth reconfigurable patch antenna for next generation wireless communication system applications. In Proceedings of the International Conference on Emerging Trends in Communication Technologies (ETCT), Dehradun, India, 18-19 November 2016.

22. Anagnostou, E.; Torres, D.; Sepulveda, N. Vanadiom dioxde switch for a reconfigurable bandwdith antenna. In Proceedings of the Loughborough Antennas \& Propagation Conference (LAPC 2017), Loughborough, UK, 13-14 November 2017.

23. Meng, L.; Wang, W.; Gao, J.; Liu, Y. Bandwidth reconfigurable antenna with three step-shaped slots. In Proceedings of the Sixth Asia-Pacific Conference on Antennas and Propagation (APCAP), Xi'an, China, 16-19 October 2017.

24. Chen, S.-Y.; Chu, Q.-X.; Shinohara, N. A bandwidth reconfigurable planar antenna for WLAN/WiMAX applications. In Proceedings of the Asia-Pacific Microwave Conference (APMC), New Delhi, India, 5-9 December 2016.

25. Horestani, A.K.; Shaterian, Z.; Naqui, J.; Martín, F.; Fumeaux, C. Reconfigurable and tunable s-shaped split-ring resonators and application in band-notched UWB antennas. IEEE Trans. Antennas Propag. 2016, 64, 3766-3776. [CrossRef]

26. Abdulraheem, Y.I.; Abdullah, A.S.; Mohammed, H.J.; Mohammed, B.A.; Abd-Alhameed, R.A. Design of radiation pattern-reconfigurable 60-GHz antenna for 5G applications. J. Telecommun. 2014, 52, 1-5.

27. Zhong-Liang, L.; Xue-Xia, Y.; Guan-Nan, T. A wideband printed tapered-slot antenna with pattern reconfigurability. IEEE Antennas Wirel. Propag. Lett. 2014, 13, 1613-1616.

28. Chen, S.L.; Qin, P.Y.; Lin, W.; Guo, Y.J. Pattern-reconfigurable antenna with five switchable beams in elevation plane. IEEE Antennas Wirel. Propag. Lett. 2018, 17, 454-457. [CrossRef]

29. Tang, M.-C.; Zhou, B.Y.; Duan, Y.; Chen, X.; Ziolkowski, R.W. Pattern-reconfigurable, flexible, wideband, directive, electrically small near-field resonant parasitic antenna. IEEE Trans. Antennas Propag. 2018, 66, 2271-2280. [CrossRef]

30. Jin, G.; Li, M.; Liu, D.; Zeng, G. A simple planar pattern-reconfigurable antenna based on arc dipoles. IEEE Antennas Wirel. Propag. Lett. 2018, 17, 1664-1668. [CrossRef]

31. Zhong, L.; Hong, J.-S.; Zhou, H.-C. A novel pattern-reconfigurable cylindrical dielectric resonator antenna with enhanced gain. IEEE Antennas Wirel. Propag. Lett. 2016, 15, 1253-1256. [CrossRef]

32. Lu, Z.-L.; Yang, X.-X.; Tan, G.-N. A multidirectional pattern reconfigurable patch antenna with CSRR on the ground. IEEE Antennas Wirel. Propag. Lett. 2017, 16, 416-419. [CrossRef]

33. Tran, H.H.; Nguyen-Trong, N.; Le, T.T.; Abbosh, A.M.; Park, H.C. Low-profile wideband high-gain reconfigurable antenna with quad-polarization diversity. IEEE Trans. Antennas Propag. 2018, 66, 3741-3746. [CrossRef]

34. Zhang, J.; Zhang, S.; Lin, X.; Fan, Y.; Pedersen, G.F. 3D radiation pattern reconfigurable phased array for transmission angle sensing in 5G mobile communication. Sensors 2018, 18, 4204. [CrossRef]

35. Chamok, N.H.; Yllmaz, M.H.; Arslan, A.; Ali, M. High-gain pattern reconfigurable MIMO antenna array for wireless handheld terminals. IEEE Trans. Antennas Propag. 2016, 64, 4306-4315. [CrossRef]

36. Wu, F.; Luk, K.M. Widband tri-polarization reconfigurable magnetoelectric dipole antenna. IEEE Trans. Antennas Propag. 2017, 65, 1633-1641. [CrossRef]

37. Lin, W.; Chen, S.L.; Ziolkowski, R.W.; Guo, Y.J. Reconfigurable, wideband, low-profile, circularly polarized antenna and array enabled by artificial magnetic conductor ground. IEEE Trans. Antennas Propag. 2018, 66, 1564-1569. [CrossRef] 
38. Tong, K.-F.; Huang, J. New proximity coupled feeding method for reconfigurable circularly polarized microstrip ring antennas. IEEE Trans. Antennas Propag. 2008, 56, 1860-1866. [CrossRef]

39. Wang, K.X.; Wong, H. A reconfigurable CP/LP antenna with cross probe feed. IEEE Antennas Wirel. Propag. Lett. 2017, 16, 669-672. [CrossRef]

40. Cai, Y.-M.; Gao, S.; Yin, Y.; Li, W.; Luo, Q. Compact-size low-profile wideband circularly polarized omnidirectional patch antenna with reconfigurable polarizations. IEEE Trans. Antennas Propag. 2016, 64, 2016-2021. [CrossRef]

41. Wu, B.; Okoniewski, M.; Hayden, C. A pneumatically controlled reconfigurable antenna with three states of polarization. IEEE Trans. Antennas Propag. 2014, 62, 5474-5484. [CrossRef]

42. Zhu, H.L.; Cheung, S.W.; Liu, X.H.; Yuk, T.I. Design of polarization reconfigurable antenna using metasurface. IEEE Trans. Antennas Propag. 2014, 62, 2891-2898. [CrossRef]

43. Row, J.-S.; Hou, M.-J. Design of polarization diversity patch antenna based on a compact reconfigurable feeding network. IEEE Trans. Antenna Propag. 2014, 62, 5349-5352. [CrossRef]

44. Mak, K.M.; Lai, H.W.; Luk, K.M.; Ho, K.L. Polarization reconfigurable circular patch antenna with a C-shaped. IEEE Trans. Antennas Propag. 2017, 65, 1388-1392. [CrossRef]

45. Al-Yasir, Y.; Abdullah, A.; Ojaroudi Parchin, N.; Abd-Alhameed, R.; Noras, J. A new polarization-reconfigurable antenna for 5G wireless communications. In Proceedings of the 9th International Conference on Broadband Communications, Networks, and Systems, Faro, Portugal, 19-20 September 2018.

46. Al-Yasir, Y.I.A.; Abdullah, A.S.; Ojaroudi Parchin, N.; Abd-Alhameed, R.A.; Noras, J.M. A new polarization-reconfigurable antenna for $5 \mathrm{G}$ applications. Electronics 2018, 7, 293. [CrossRef]

47. Qin, P.Y.; Wei, F.; Guo, Y.J. A wideband-to-narrowband tunable antenna using a reconfigurable filter. IEEE Trans. Antennas Propag. 2015, 63, 2282-2285. [CrossRef]

48. Kingsly, S.; Thangarasu, D.; Kanagasabai, M.; Alsath, M.G.; Thipparaju, R.R.; Palaniswamy, S.K.; Sambandam, P. Multiband reconfigurable filtering monopole antenna for cognitive radio applications. IEEE Antennas Wirel. Propag. Lett. 2018, 17, 1416-1420. [CrossRef]

49. Hussain, R.; Sharawi, M.S. An integrated frequency reconfigurable antenna for cognitive radio application. Radioengineering 2017, 26, 746-754.

50. Bitchikh, M.; Rili, W.; Mokhtar, M. An UWB to narrow band and BI-bands reconfigurable octogonal antenna. Prog. Electromagn. Res. Lett. 2018, 74, 69-75. [CrossRef]

51. Hussain, R.; Sharawi, M.S. A cognitive radio reconfigurable MIMO and sensing antenna system. IEEE Antennas Wirel. Propag. Lett. 2015, 14, 257-260. [CrossRef]

52. Hussain, R.; Sharawi, M.S. Integrated reconfigurable multiple-input-multiple-output antenna system with an ultra-wideband sensing antenna for cognitive radio platforms. IET Microw. Antennas Propag. 2015, 9 , 940-947. [CrossRef]

53. Chacko, P.; Augustin, G.; Denidni, T.A. Electronically reconfigurable uniplanar antenna for cognitive radio applications. IET Microw. Antennas Propag. 2015, 14, 213-216.

54. Nachouane, H.; Najid, A.; Tribak, A.; Riouch, F. Reconfigurable and tunable filtenna for cognitive LTE femtocell base stations. Int. J. Microw. Sci. Technol. 2016. [CrossRef]

55. Nachouane, H.; Najid, A.; Tribak, A.; Riouch, F. Dual port antenna combining sensing and communication tasks for cognitive radio. Int. J. Electron. Telecommun. 2016, 62, 121-127. [CrossRef]

56. Purisima, M.C.L.; Salvador, M.; Augstin, S.G.P.; Cunanon, M.T. Frequency and pattern reconfigurable antennas for community cellular application. In Proceedings of the IEEE Conference TENCON, Singapore, 22-25 November 2016.

57. Nguyen-Trong, N.; Hall, L.; Fumeaux, C. A frequency- and pattern-reconfigurable center-shorted microstrip antenna. IEEE Antennas Wirel. Propag. Lett. 2016, 15, 1955-1958. [CrossRef]

58. Trong, N.N.; Hall, L.; Fumeaux, C. A dual-band dual-pattern frequency-reconfigurable antenna. Microw. Opt. Tech. Lett. 2017, 59, 2710-2715. [CrossRef]

59. Zainarry, S.N.M.; Nguyen-Trong, N.; Fumeaux, C. A frequency and pattern-reconfigurable two-element array antenna. IEEE Antennas Wirel. Propag. Lett. 2018, 17, 617-620. [CrossRef]

60. Li, P.K.; Shao, Z.H.; Wang, Q.; Cheng, Y.J. Frequency- and pattern reconfigurable antenna for multistandard wireless applications. IEEE Antennas Wirel. Propag. Lett. 2015, 14, 333-336. [CrossRef] 
61. Sahu, N.K.; Sharma, A.K. An investigation of pattern and frequency reconfigurable microstrip slot antenna using PIN diodes. In Proceedings of the 2017 Progress in Electromagnetics Research Symposium-Spring (PIERS), St. Petersburg, Russia, 22-25 May 2017; pp. 971-976.

62. Han, L.; Wang, C.; Zhang, W.; Ma, R.; Zeng, Q. Design of frequency- and pattern-reconfigurable wideband slot antenna. Int. J. Antennas Propag. 2018, 1-7. [CrossRef]

63. Majid, H.A.; Rahim, M.K.A.; Hamid, M.R.; Ismail, M.F. Frequency and pattern reconfigurable slot antenna. IEEE Trans. Antennas Propag. 2014, 62, 5339-5343. [CrossRef]

64. Zhu, Z.; Wang, P.; You, S.; Gao, P. A flexible frequency and pattern reconfigurable antenna for wireless systems. Prog. Electromagn. Res. Lett. 2018, 76, 63-70.

65. Ye, M.; Gao, P. Back-to-back F semicircular antenna with frequency and pattern reconfigurability. Electron. Lett. 2015, 51, 2073-2074. [CrossRef]

66. Pan, J.Y.; Ma, Y.; Xiong, J.; Hou, Z.; Zeng, Y. A compact reconfigurable microstrip antenna with frequency and radiation pattern selectivity. Microw. Opt. Tech. Lett. 2015, 57, 2848-2854. [CrossRef]

67. Li, W.; Bao, L.; Zhai, Z.; Li, Y.; Li, S. An enhanced frequency and radiation pattern reconfigurable antenna for portable device applications. In Proceedings of the 31st International Review of Progress in Applied Computational Electromagnetics (ACES), Williamsburg, VA, USA, 22-26 March 2015.

68. Pan, Y.; Ma, Y.; Xiong, J.; Hou, Z.; Zeng, Y. A compact antenna with frequency and pattern reconfigurable characteristics. Microw. Opt. Tech. Lett. 2017, 59, 2467-2471.

69. Liang, B.; Sanz-Izquierdo, B.; Parker, E.A.; Batchelor, J.C. A frequency and polarization reconfigurable circularly polarized antenna using active EBG structure for satellite navigation. IEEE Trans. Antennas Propag. 2015, 63, 33-40. [CrossRef]

70. Huang, Y.C.; Ma, X.; Pan, W.; Luo, X. A low profile polarization reconfigurable dipole antenna using tunable electromagnetic band-gap surface. Microw. Opt. Tech. Lett. 2014, 56, 1281-1285.

71. Chen, M.S.; Zhang, Z.X.; Wu, X.L. Design of frequency-and polarization-reconfigurable antenna based on the polarization conversion metasurface. IEEE Antennas Wirel. Propag. Lett. 2018, 17, 78-81.

72. Niture, V.; Govind, P.A.; Mahajan, S.P. Frequency and polarisation reconfigurable square ring antenna for wireless application. In Proceedings of the 2016 IEEE Region, 10 Conference (TENCON), Singapore, 22-25 November 2016.

73. Nguyen-Trong, N.; Hall, L.; Fumeaux, C. A frequency- and polarization-reconfigurable stub-loaded microstrip patch antenna. IEEE Trans. Antennas Propag. 2015, 63, 5235-5240. [CrossRef]

74. Liu, J.; Li, J.; Xu, R. Design of very simple frequency and polarisation reconfigurable antenna with finite ground structure. Electron. Lett. 2018, 54, 187-188. [CrossRef]

75. Rahman, M.A.; Nishiyama, E.; Toyoda, I. A frequency diversity reconfigurable antenna with circular polarization switching capability. In Proceedings of the 2017 IEEE International Symposium on Antennas and Propagation \& USNC/URSI National Radio Science Meeting, San Diego, CA, USA, 9-14 July 2017; pp. 1367-1368.

76. Kumar, M.S.; Choukiker, Y.K. Frequency and polarization reconfigurable antenna using BLC feed network. In Proceedings of the 2017 IEEE International Conference on Antenna Innovations \& Modern Technologies for Ground, Aircraft and Satellite Applications (iAIM), Bangalore, India, 24-26 November 2017.

77. Narbudowicz, A.; Bao, X.L.; Ammann, M.J. Omnidirectional microstrip patch antenna with reconfigurable pattern and polarization. IET Microw. Antennas Propag. 2014, 8, 872-877. [CrossRef]

78. Gu, C.; Gao, S.; Liu, H.; Luo, Q.; Loh, T.-H.; Sobhy, M.; Li, J.; Wei, G.; Xu, J.; Qin, F.; et al. Compact smart antenna with electronic beam-switching and reconfigurable polarizations. IEEE Trans. Antennas Propag. 2015, 63, 5325-5333. [CrossRef]

79. Yang, K.; Loutridis, A.; Bao, X. Printed inverted-F antenna with reconfigurable pattern and polarization. In Proceedings of the 10th European Conference on Antennas and Propagation (EuCAP), Davos, Switzerland, 10-15 April 2016.

80. Lin, W.; Wong, H.; Ziolkowski, R.W. Circularly-polarized antenna with reconfigurable broadside and conical beams facilitated by a mode switchable feed network. IEEE Trans. Antennas Propag. 2018, 66, 996-1001. [CrossRef]

81. Chen, A.; Ning, X.; Wang, L.; Zhang, Z. A design of radiation pattern and polarization reconfigurable antenna using metasurface. In Proceedings of the 2017 IEEE Asia Pacific Microwave Conference (APMC), Kuala Lumpar, Malaysia, 13-16 November 2017. 
82. Yi, X.; Huitema, L.; Wong, H. Polarization and pattern reconfigurable cuboid quadrifilar helical antenna. IEEE Trans. Antennas Propag. 2018, 66, 2707-2715. [CrossRef]

83. Trong, N.N.; Mobashsher, A.T.; Abbosh, A.M. Reconfigurable shorted patch antenna with polarization and pattern diversity. In Proceedings of the 2018 Australian Microwave Symposium (AMS), Brisbane, Australia, 6-7 February 2018.

84. Lin, W.; Wong, H. Polarization reconfigurable wheel-shaped antenna with conical-beam radiation pattern. IEEE Trans. Antennas Propag. 2015, 63, 491-499. [CrossRef]

85. Rodrigo, D.; Cetiner, B.A.; Jofre, L. Frequency, radiation pattern and polarization reconfigurable antenna using a parasitic pixel layer. IEEE Trans. Antennas Propag. 2014, 62, 3422-3427. [CrossRef]

86. Selvam, Y.P.; Elumalai, L.; Alsath, G.; Kanagasabai, M.; Kingsly, S.; Subbburaj, S. Novel frequency- and pattern-reconfigurable rhombic patch antenna with switchable polarization. IEEE Antennas Wirel. Propag. Lett. 2017, 16, 1639-1642. [CrossRef]

(C) 2019 by the authors. Licensee MDPI, Basel, Switzerland. This article is an open access article distributed under the terms and conditions of the Creative Commons Attribution (CC BY) license (http:/ / creativecommons.org/licenses/by/4.0/). 